\title{
Osteocalcin Level in Children with Steroid Dependent/Frequently Relapsing and Steroid Resistant Nephrotic Syndrome
}

\author{
Emad E Ghobrial, ${ }^{1,}$ Hanan Abdel-Aziz, ${ }^{1}$ Riham H El Sayed, ${ }^{1}$ and Athar M Abdel-Aliem ${ }^{1}$ \\ ${ }^{1}$ Pediatric Nephrology Clinic, Children's Hospital, Faculty of Medicine, Cairo University, Egypt \\ "Corresponding author: Dr. Emad E. Ghobrial, 72nd Mohamed Abdel-Moneam St, off Rayel St, Helwan, Cairo, Egypt. Tel: +02-25563210, E-mail: dr.emademil@yahoo.com
}

Received 2017 May 29; Revised 2017 July 17; Accepted 2017 September 04.

\begin{abstract}
Background: Children with nephrotic syndrome (NS) may be at risk for metabolic bone disease because of biochemical derangement caused by renal disease as well as steroid therapy. Osteocalcin $(\mathrm{OC})$ functions as an inhibitor of bone mineralization. We aimed to evaluate linear growth and bone turnover markers (including serum osteocalcin) in children with steroid-dependant/frequentlyrelapsing and steroid resistant NS in comparison to a matched control group.

Methods: Our study was a cross-sectional study conducted at children's hospital, Cairo University, Egypt from July 2014 to August 2015. The study included 60 patients, aged 2 - 15 years recruited from outpatient nephrology clinic. Twenty eight age- and sexmatched healthy children were included as a control group. Serum OC was measured by immune-radiometric assay.

Results: Serum OC levels were significantly higher in both SDNS/FRNS and SRNS than in control group, with P value 0.02 and 0.01 , respectively. There was statistically significant negative correlation between OC and serum calcium. There was a negative correlation between height for age percentile and number of relapses. There were also negative correlations between height for age percentile and steroids, cyclophosphamide and cyclosporine duration of treatment. We found that both of our patients groups (SDNS/FRNS and SRNS) showed lower height for age percentile compared to control group ( $\mathrm{P}=0.017$ and 0.001 respectively).

Conclusions: Height as a growth parameter is more affected when recurrent relapses occur with multiple courses of steroid therapy. Use of OC as screening tool is recommended for bone turnover while patients on steroids.
\end{abstract}

Keywords: Osteocalcin, Nephrotic Syndrome, Children

\section{Background}

Nephrotic syndrome(NS) is a clinical condition characterized by massive proteinuria, hypoalbuminemia, hypercholesterolemia, and generalized edema (1).

Children with NS may be at risk for metabolic bone disease because of biochemical derangement caused by renal disease as well as steroid therapy (2).

Previous studies show that some markers of bone mineral density (BMD) were affected during steroid therapy (after beginning and within three months of therapy). These markers include mean serum calcium which is found to be significantly lower than those at the beginning of therapy. Mean serum alkaline phosphatase and urine calcium/ creatinine ratio $(\mathrm{Ca} / \mathrm{Cr})$ are significantly increased in comparison to the beginning of therapy (3).

Osteocalcin (OC) is a non-collagenous, 49 amino acid glutamate-rich polypeptide bone matrix with a molecular weight of about $5800 \mathrm{kDa}(4)$.

OC functions as an inhibitor of bone mineralization. It inhibits the precipitation of calcium salts from saturated solutions (5). The serum concentrations of bone-specific alkaline phosphatase and OC reflect cellular activity of osteoblasts (6).
OC level is related to increased bone turnover and it decreases in patients taking anti-resorptive agents (biphosphonates or hormone replacement therapy (HRT)); this usually occurs within 3- 6 months after therapy begins. Decreasing levels indicate effective response to treatment (7).

The aim of this study was to evaluate linear growth and bone turnover markers (calcium, phosphorous, alkaline phosphatase and serum osteocalcin) in children with steroid-dependant/ frequently-relapsing (SRNS/FRNS) and steroid resistant nephrotic syndrome (SRNS) in comparison to a matched control group. It aimed also to assess whether there is a significant affection on growth regarding height and weight of these patients under long-term steroid therapy in comparison to the control group.

\section{Methods}

Our study is a cross-sectional study conducted at University children's hospital, faculty of Medicine, Cairo University, Egypt from July 2014 to August 2015. It included 60 patients, aged 2 - 15 years recruited from outpatient nephrology clinic. Duration of the disease had to be not 
less than six months. Informed consent was taken from each parent to participate in the study.

Twenty eight age- and sex-matched healthy children were included as a control group. They were recruited from the follow-up and surgical clinics of the hospital after consent from their parents. They had no history of chronic illness or any received medications known to affect bone turnover.

Patients with renal impairment or renal tubular defect, patients with steroid-sensitive nephrotic syndrome, patients with congenital nephrotic syndrome, patients with duration of the disease less than 6 months and with other causes of low bone density (vitamin D deficiency, metabolic disorders such as irregularities in thyroid and parathyroid hormones and medications such as anticonvulsants, etc.) were excluded from the study.

Patients were divided into 3 groups; Group A included 30 children with SDNS/FRNS, Group B included 30 children with SRNS and Group C included 28 matched children of the same age and sex as the control group. SRNS is defined as failure to develop remission after six weeks of prednisone at dose of $60 \mathrm{mg} / \mathrm{m}^{2} /$ day, SDNS is defined as acquiring two consequent relapses during corticosteroid withdrawal or 14 days after treatment was completed and FRNS is defined as acquiring of two or more relapses within 6 months of initial relapse or four or more relapses after 10 months of remission (8).

The sample size provided a power of $80 \%$ assuming a mean control OC level of $20 \mathrm{ng} / \mathrm{mL}$ and intergroup variation of at least $25 \%$

Patients were subjected to the following;

- Full history taking, including age of onset, duration of illness, number of relapses, presence of hypertension and hematuria, symptoms suggestive of osteoporosis (e.g. back pain, spinal deformity, recurrent long bone fractures, etc.), history of calcium and vitamin D supplementation during course of the disease and detailed information about the modalities of therapy and pattern of steroid response.

- Clinical examination, including; height and weight for age percentiles according to Egyptian growth curves to assess the growth status of the children, assessment of blood pressure and presence of oedema.

- Laboratory investigations, including; serum urea and creatinine, serum albumin, cholesterol, serum calcium, phosphorus and serum alkaline phosphatase (analyzed by Dimension auto-analyzer). Protein/creatinine ratio in urine was done using Beckman Synchron CX9 (Beckman Coulter). Serum osteocalcin was measured by immuneradiometric assay (IRMA).

\subsection{Statistical Analysis}

All data were collected on standardized forms, entered in a computerized database, and analyzed with statistical software packing using Microsoft Excel 2013 and SPSS version 22.0.

Results were statistically presented in terms of (Range, mean, median, standard deviation and percentage). Continuous data (of both groups) were compared with paired T-tests and categorical data (parametrical data) by Pearson's chi-square test was performed. A P value $<0.05$ was considered statistically significant (9).

\section{Results}

The age of the SDNS/FRNS group was $8.5 \pm 3$ years (range: 2 - 15), the age of the SRNS group was $9.4 \pm 3$ years (range: 2 - 15) while of the control group was $7 \pm$ 3 years (range: $3-14$ ) with no statistically significant differences between the groups. Twenty (66.7\%) patients of the SDNS/FRNS group were males and 10 (33.3\%) females, 19 (63.3\%) patients of the SRNS group were males and 11(36.7\%) females, while 13 (46.4\%) of the control group were males and $15(53.6 \%)$ females.

Age of onset was $3.6 \pm 2.4$ years in SDNS/FRNS group and $4.4 \pm 2.6$ in SRNS patients. Number of relapses during the whole course of the disease was 4 (range; 2 -14) in both SDNS/FRNS and SRNS groups. Twenty (66.7\%) patients of the SDNS/FRNS group and 16 (53.3\%) patients of the SRNS group were in remission at the time of the study.

Table 1 shows anthropometric measures of each of the study groups separately in comparison to control group. Regarding height of our patients, both of our patient groups (SDNS/FRNS and SRNS) showed lower height for age percentile compared to control group $(\mathrm{P}=0.017$ and 0.001 , respectively). In addition, we found that $50 \%$ of our patients were below 5 th percentile for height.

Table 2 shows number of patients who had bone affections before and after starting of steroid therapy and number of patients receiving prophylactic calcium and vitamin D during childhood period.

Table 3 shows duration of therapy with steroid and other immunosuppressive drugs in both study groups.

Table 4 shows laboratory results in both study groups in comparison to control group. Serum OC levels are significantly higher in both SDNS/FRNS and SRNS than in control group, with P value 0.02 and 0.01 , respectively.

When we divided the 60 patients in our study according to the state of remission or relapse at the time of the study, we found that mean serum OC level in relapsed patients was $20.3 \pm 16.6 \mathrm{ng} / \mathrm{mL}$ which was lower than the level in patients in remission $(30.2 \pm 16 \mathrm{ng} / \mathrm{mL})$. This difference is statistically significant $(\mathrm{P}=0.001)$. 
Table 1. Anthropometric Measures of Each Study Group in Comparison to Control Group

\begin{tabular}{|c|c|c|c|}
\hline Variables & Study Group & Control Group & P Value \\
\hline Weight for age percentile & & $51.8 \pm 21.7$ & \\
\hline SDNS/FRNS & $70.42 \pm 26.7$ & & $0.001^{* *}$ \\
\hline SRNS & $63.7 \pm 28.6$ & & 0.082 \\
\hline Height for age percentile & & $35.7 \pm 25.1$ & \\
\hline SDNS/FRNS & $20.2 \pm 22.7$ & & $0.017^{*}$ \\
\hline SRNS & $9.9 \pm 18$ & & $0.001^{* *}$ \\
\hline BMI & & $17.3 \pm 2.9$ & \\
\hline SDNS/FRNS & $22.3 \pm 4.4$ & & $0.001^{* *}$ \\
\hline SRNS & $23.8 \pm 6.8$ & & $0.001^{* *}$ \\
\hline
\end{tabular}

Abbreviations: BMI, Body Mass Index; SRNS, Steroid-Resistant Nephrotic Syndrome; SDNS/FRNS, Steroid-Dependent / Frequent-Relapsing Nerphrotic Syndrome.

Table 2. Bone Affection, Calcium and Vitamin D Supplementation Before and After Treatment

\begin{tabular}{|c|c|c|c|}
\hline Variables & SDNS/FRNS & SRNS & Total \\
\hline No bone affection before steroid treatment & $30(100)$ & $30(100)$ & $60(100)$ \\
\hline \multicolumn{4}{|l|}{ Bone affection after steroid treatment } \\
\hline No & $25(83.3)$ & $25(83.3)$ & $50(83.8)$ \\
\hline Bone aches & $4(13.5)$ & $3(10)$ & $7(11.7)$ \\
\hline Calcium and vitamin D supplement before treatment & $14(46.7)$ & $8(26.7)$ & $22(36.7)$ \\
\hline Calcium supplementation only after treatment & $29(96.7)$ & $30(100)$ & $59(98.3)$ \\
\hline Calcium and vitamin D supplementation after treatment & $22(73.3)$ & $19(63.3)$ & $41(68.3)$ \\
\hline
\end{tabular}

Abbreviation: SRNS, Steroid-Resistant Nephrotic Syndrome; SDNS/FRNS, Steroid-Dependent / Frequent-Relapsing Nerphrotic Syndrome.

${ }^{\mathrm{a}}$ Values are expressed as No. (\%).

Table 3. Duration of Steroids and Other Immunosuppressive Drugs

\begin{tabular}{lcc}
\hline Variables & SDNS/FRNS, y & SRNS, y \\
\hline Steroid & $4 \pm 2.5$ & $3.9 \pm 2.7$ \\
\hline Azathioprine & $0.5 \pm 1$ & $0.34 \pm 0.65$ \\
\hline Cyclophosphamide & $0.9 \pm 0.16$ & $0.2 \pm 0.28$ \\
\hline Mycophenolate & $0.18 \pm 0.57$ & $0.32 \pm 0.8$ \\
\hline Cyclosporine & $0.32 \pm 1.2$ & $1.5 \pm 1.3$ \\
\hline Levamisol & $0.72 \pm 1.1$ & $0.3 \pm 0.9$ \\
\hline
\end{tabular}

Abbreviations: SRNS, Steroid-Resistant Nephrotic Syndrome; SDNS/FRNS Steroid-Dependent / Frequent-Relapsing Nerphrotic Syndrome.

In both case and control groups, there was statistically significant negative correlation between OC and serum calcium $(\mathrm{r}=-0.4, \mathrm{P}=0.0001)$ as shown in Figure 1 , while there was no significant correlation between OC and phos- phorus and alkaline phosphatase.

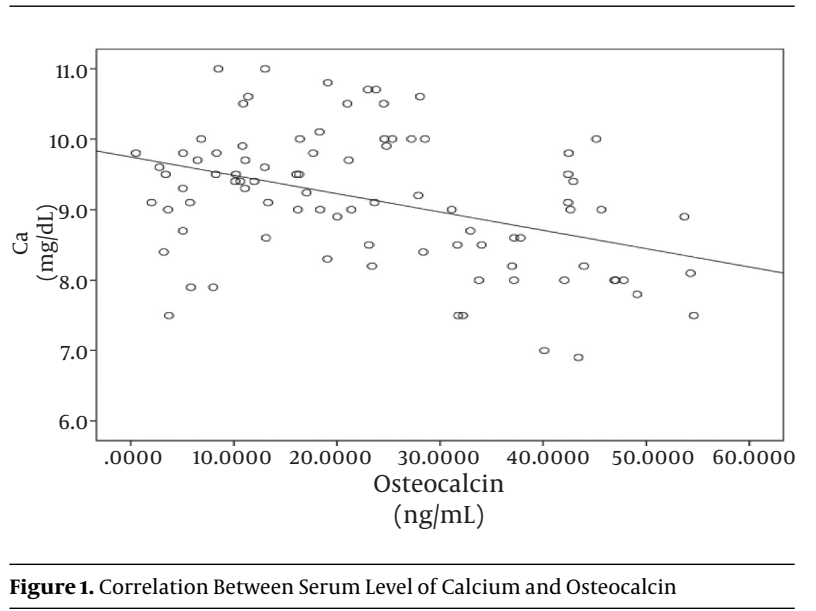

There was a negative correlation between height for 


\begin{tabular}{|c|c|c|c|}
\hline Variables & Study Group & Control Group & P Value \\
\hline Calcium, mg/dL & & $9.8 \pm 0.7$ & \\
\hline SDNS/FRNS & $8.9 \pm 0.8$ & & $0.0001^{* *}$ \\
\hline SRNS & $8.9 \pm 0.8$ & & $0.0001^{* *}$ \\
\hline Phosphorous, mg/dL & & $4.2 \pm 0.7$ & \\
\hline SDNS/FRNS & $4.1 \pm 0.8$ & & 0.6 \\
\hline SRNS & $4.3 \pm 0.8$ & & 0.8 \\
\hline ALP, $\mathbf{U} / \mathbf{L}$ & & $217 \pm 103$ & \\
\hline SDNS/FRNS & $273 \pm 120$ & & 0.63 \\
\hline SRNS & $293 \pm 153$ & & $0.02^{*}$ \\
\hline OC, $\mu \mathrm{g} / \mathbf{L}$ & & $17.7 \pm 6.6(19.57 / 12.62-24.04)$ & \\
\hline SDNS/FRNS (median/IQR) & $26.2 \pm 17.6(11.30 / 6.85-27.24)$ & & $0.02^{*}$ \\
\hline SRNS (median/IQR) & $26 \pm 16.3(11.56 / 4.49-28.29)$ & & $0.01^{*}$ \\
\hline BUN, mg/dL & & $15.5 \pm 8$ & \\
\hline SDNS/FRNS & $13.2 \pm 6.9$ & & 0.25 \\
\hline SRNS & $13.9 \pm 9.6$ & & 0.5 \\
\hline Creatinine, mg/dL & & $0.55 \pm 0.2$ & \\
\hline SDNS/FRNS & $0.53 \pm 0.2$ & & 0.78 \\
\hline SRNS & $0.6 \pm 0.2$ & & 0.5 \\
\hline
\end{tabular}

Abbreviations: ALP, Alkaline Phosphatase; IQR, Interquartile Range; OC, Osteocalcin, BUN, Blood Urea Nitrogen; SRNS, Steroid-Resistant Nephrotic Syndrome; SDNS/FRNS, Steroid-Dependent / Frequent-Relapsing Nerphrotic Syndrome.

age percentile and number of relapses $(\mathrm{r}=-0.25, \mathrm{P}=0.05)$. There is also a negative correlation between height for age percentile and duration of steroid therapy $(r=-0.27$, $\mathrm{P}=0.05)$. There were also negative correlations between height for age percentile and cyclophosphamide $(r=-0.26$, $\mathrm{P}=0.044)$ and cyclosporine duration of treatment $(\mathrm{r}=-0.3$, $\mathrm{P}=0.02)$.

\section{Discussion}

Long-term use of corticosteroids in children with NS may lead to bone metabolism disorders, whose mechanisms are underlain by both steroid therapy and biochemical changes due to proteinuria that influences bone turnover and mineralization (10).

Raisz (2005) (11) stated that glucocorticoids (GC) modify the strictly regulated balance of bone metabolism. Secondary osteoporosis is caused by a relative increase of bone resorption over bone formation (12). This results in reduced osteoblastic differentiation and osteoblastic activity by for example suppressing the synthesis of type I collagen, a major component of bone matrix, as well as lowering osteoblastic activity by accelerating apoptosis. De- pressed bone formation is considered to be the main skeletal target of GC action (13).

Other contributing factors are decrease of muscle mass, sex hormone levels and a suppression of the somatotrophic axis accelerate the onset of GC-induced osteoporosis (14).

During the current study, male patients represented percentage of $66.7 \%$ and $63.3 \%$ of patients with SDNS/FRNS and SRNS respectively. In agreement with our study, Hammad et al. (2013) (15) found that $65 \%$ of SRNS were males and Shah et al. (2015) (16) found that $66.7 \%$ of their SRNS patients were males.

There was statistically higher weight for age percentile in SDNS/FRNS patients compared to control group ( $\mathrm{P}=$ 0.005); while, there was no statistical difference between SRNS patient and control group. In both SDNS/FRNS and SRNS, we also found that BMI was higher in both patients groups when compared to control group $(\mathrm{P}=0.0001$ and 0.0001 , respectively).

Moon et al. (2014) (17) found that the children with NS were heavier than the controls $(\mathrm{P}=0.022)$ and had greater body fat percentage SDS $(\mathrm{P}=0.008)$.

We found that both of our patients groups (SDNS/FRNS 
and SRNS) showed lower height for age percentile compared to control group $(\mathrm{P}=0.017$ and 0.00 respectively). In addition, we found that $50 \%$ of our patients were below 5 th percentile for height.

In our study, we found that height of all nephrotic patients was negatively correlated to duration of steroid, cyclophosphamide and cyclosporine therapy $(\mathrm{P}=0.05, \mathrm{P}=$ 0.044 and 0.02 respectively). The explanation of this may be due to the association between the several prolonged and repeated courses of steroids therapy in combination with cyclophosphamide and cyclosporine. In addition we found that there was statistically negative correlation between height for age percentile and number of relapses ( $P$ value $=0.05$ )

This matched with what Ribeiro et al. (2015) (18) noted. They found that growth and spine bone mineral density (BMD) were both negatively associated with the cumulative dose of steroids ( $\mathrm{P}=0.001$ and $\mathrm{P}=0.037$, respectively).

In contrary, Leroy et al. (2009) (19) followed 64 children with SDNS receiving long-term cyclosporine and steroid therapy which were retrospectively analyzed. During the 10-year follow-up period, height standard deviation score (HSDS) remained in the normal range in 47 patients but was below -2 SD in 17 patients.

Only 3 (5\%) patients of our study group had bone fractures (proved by plain X-ray) during the course of the disease and under treatment of steroids. By history, two of them were on irregular dose of calcium only without vitamin $\mathrm{D}$ and one did not receive any calcium or vitamin D supplement treatment. This was found when Phan et al. (2014) (20) studied 54 children followed to 12 months after steroid initiation. Three of 54 children with radiographs had incident vertebral fracture at 1 year.

There were significantly lower calcium levels in both SDNS/FRNS and SRNS patient groups compared to the control group ( $\mathrm{P}=0.0001,0.0001$, respectively). As regarding serum alkaline phosphatase (ALP) in our study, we found higher ALP levels in both SDNS/FRNS and SRNS patients compared to control group but with statistical significance for only SRNS patients $(\mathrm{P}=0.02)$.

Osteocalcin is a non-collagenous protein of bone matrix, and it is a good marker of bone formation and a sensitive indicator of inhibitory effects of corticosteroids (21). It is believed that it acts on the bone matrix to regulate mineralization (22).

In our study, we found higher OC levels in both SDNS/FRNS and SRNS patient groups compared to the control group ( $\mathrm{P}=0.02$ and 0.01 respectively). We also found that OC levels were negatively correlated to serum calcium levels of the whole patients $(\mathrm{P}$ value $=0.0001)$.

The studies in adults have shown that a single oral dose of $2.5 \mathrm{mg}$ prednisone exerts an almost immediate effect on the serum OC level (23). Biyikli et al. (2004) (24) found a negative influence of long term corticosteroid therapy on the OC level in children with nephrotic syndrome.

When we divided the 60 patients in our study according to the state during the study period if they were in remission or relapse, we found that mean serum OC level in relapsed patients was $20.3 \pm 16.6 \mathrm{ng} / \mathrm{mL}$ which is lower than its mean level in patients in remission (30.2 $\pm 16 \mathrm{ng} / \mathrm{mL}$ ). This difference is statistically significant $(\mathrm{P}=$ 0.001).

In agreement with our study, Mohamed and AbdelLatif (2011) (2), studied 30 NS patients in a case-control study and they found that children with NS, whether in one group or classified into frequent relapse and infrequent relapse, had significantly higher serum OC than controls ( $P$ value $=0.0001$ ).

In another study done by Panczyk-Tomaszewska et al. (25), 25 children with idiopathic NS were observed over 1year, they were treated with prednisone (a mean starting dose of $0.7 \pm 0.5 \mathrm{mg} / \mathrm{kg} / 48 \mathrm{~h}$ ) and vitamin D (800 IU/24 h) and all tests weres done during remission. It was found that serum calcium, phosphorus, alkaline phosphatase and OC were inappreciably different at the beginning and end of the therapy time.

A major limitation of this study was the small sample size and lack of follow up. Also, in our study we did not do dual-energy X-ray absorptiometry (DEXA) scan or bone ALP which are not available in our hospital, plus these are too expensive.

\subsection{Conclusion}

Patients having nephrotic syndrome on long-term steroid use (SDNS/FRNS and SRNS) are at higher risk of bone metabolism disorders. There is a higher bone turnover in patients treated with high doses of steroids which may affect patient's growth and height, so it is important to follow up the growth parameters including height, weight and BMI in all patients with nephrotic syndrome. Height as a growth parameter is more affected when recurrent relapses occur with multiple courses of steroid therapy. Careful evaluation of BMD and early prophylactic supplementation with calcium and vitamin $\mathrm{D}$ and regular follow up of its level with increasing the dose if there is any abnormality are necessary. Use of OC as screening tool is recommended for bone turnover while patients on steroids.

\section{Acknowledgments}

We thank all the patients participated in the study and their parents. 


\section{References}

1. Burgstein JM. In: Nelson Textbook of Pediatrics. 18th ed. Behrman RE, Kliegman RM, Jenson HB, editors. Philadelphia: Saunders; 2008. pp. 2340-2.Nephrotic syndrome.

2. Mohamed GB, Abdel-Latif EA. Serum osteoprotegerin (OPG) in children with primary nephrotic syndrome. Saudi J Kidney Dis Transpl. 2011;22(5):955-62. [PubMed: 21912025].

3. Kosan C, Ayar G, Orbak Z. Effects of steroid treatment on bone mineral metabolism in children with glucocorticoid-sensitive nephrotic syndrome. West Indian Med J. 2012;61(6):627-30. [PubMed: 23441359].

4. Lee NK, Sowa H, Hinoi E, Ferron M, Ahn ID, Confavreux C, et al. Endocrine regulation of energy metabolism by the skeleton. Cell. 2007;130(3):456-69. doi: 10.1016/j.cell.2007.05.047. [PubMed: 17693256].

5. Willems BA, Vermeer C, Reutelingsperger CP, Schurgers LJ. The realm of vitamin $\mathrm{K}$ dependent proteins: shifting from coagulation toward calcification. Mol Nutr Food Res. 2014;58(8):1620-35. doi: 10.1002/mnfr.201300743. [PubMed: 24668744].

6. Bergmann P, Body JJ, Boonen S, Boutsen Y, Devogelaer JP, Goemaere $S$, et al. Evidence-based guidelines for the use of biochemical markers of bone turnover in the selection and monitoring of bisphosphonate treatment in osteoporosis: a consensus document of the Belgian Bone Club. Int J Clin Pract. 2009;63(1):19-26. doi: 10.1111/j.17421241.2008.01911.x. [PubMed: 19125989].

7. Harris SS, Soteriades E, Dawson-Hughes B, Framingham Heart S, Boston Low-Income Elderly Osteoporosis S. Secondary hyperparathyroidism and bone turnover in elderly blacks and whites. J Clin Endocrinol Metab. 2001;86(8):3801-4. doi: 10.1210/jcem.86.8.7783. [PubMed: 11502814].

8. Primary nephrotic syndrome in children: clinical significance of histopathologic variants of minimal change and of diffuse mesangial hypercellularity. A Report of the International Study of Kidney Disease in Children. Kidney Int. 1981;20(6):765-71. doi: 10.1038/ki.1981.209. [PubMed: 7334749].

9. Bolton S, Bon C. Pharmaceutical statistics: Practical and Clinical Applications. 5th ed. Florida: Taylor and Francis group; 2009.

10. Feber J, Gaboury I, Ni A, Alos N, Arora S, Bell L, et al. Skeletal findings in children recently initiating glucocorticoids for the treatment of nephrotic syndrome. Osteoporos Int. 2012;23(2):751-60. doi: 10.1007/s00198-011-1621-2. [PubMed: 21494860].

11. Raisz LG. Pathogenesis of osteoporosis: concepts, conflicts, and prospects. J Clin Invest. 2005;115(12):3318-25. doi: 10.1172/JCI27071. [PubMed: 16322775].

12. Schacke H, Docke WD, Asadullah K. Mechanisms involved in the side effects of glucocorticoids. Pharmacol Ther. 2002;96(1):23-43. doi: 10.1016/S0163-7258(02)00297-8. [PubMed: 12441176].

13. Canalis E, Mazziotti G, Giustina A, Bilezikian JP. Glucocorticoid- induced osteoporosis: pathophysiology and therapy. Osteoporos Int. 2007;18(10):1319-28. doi: 10.1007/s00198-007-0394-0. [PubMed: 17566815].

14. Henneicke H, Gasparini SJ, Brennan-Speranza TC, Zhou H, Seibel MJ. Glucocorticoids and bone: local effects and systemic implications. Trends Endocrinol Metab. 2014;25(4):197-211. doi: 10.1016/j.tem.2013.12.006. [PubMed: 24418120].

15. Hammad A, Yahia S, Gouida MS, Bakr A, El-farahaty RM. Low expression of glucocorticoid receptors in children with steroidresistant nephrotic syndrome. Pediatr Nephrol. 2013;28(5):759-63. doi: 10.1007/s00467-012-2385-4. [PubMed: 23299233].

16. Shah SS, Akhtar N, Sunbleen F, ur Rehman MF, Ahmed T. Histopathological Patterns in Paediatric Idiopathic Steroid Resistant Nephrotic Syndrome. J Ayub Med Coll Abbottabad. 2015;27(3):633-6. [PubMed: 26721026].

17. Moon RJ, Gilbert RD, Page A, Murphy L, Taylor P, Cooper C, et al. Children with nephrotic syndrome have greater bone area but similar volumetric bone mineral density to healthy controls. Bone. 2014;58:10813. doi: 10.1016/j.bone.2013.10.012. [PubMed: 24145304].

18. Ribeiro D, Zawadynski S, Pittet LF, Chevalley T, Girardin E, Parvex P. Effect of glucocorticoids on growth and bone mineral density in children with nephrotic syndrome. Eur J Pediatr. 2015;174(7):911-7. doi: 10.1007/s00431-014-2479-z. [PubMed: 25573461].

19. Leroy V, Baudouin V, Alberti C, Guest G, Niaudet P, Loirat C, et al Growth in boys with idiopathic nephrotic syndrome on long-term cyclosporin and steroid treatment. Pediatr Nephrol. 2009;24(12):2393400. doi: 10.1007/s00467-009-1266-y. [PubMed: 19669799].

20. Phan V, Blydt-Hansen T, Feber J, Alos N, Arora S, Atkinson S, et al. Skeletal findings in the first 12 months following initiation of glucocorticoid therapy for pediatric nephrotic syndrome. Osteoporos Int. 2014;25(2):627-37. doi: 10.1007/s00198-013-2466-7. [PubMed: 23948876].

21. Clemens TL, Karsenty G. The osteoblast: an insulin target cell controlling glucose homeostasis.J Bone Miner Res. 2011;26(4):677-80. doi: 10.1002/jbmr.321. [PubMed: 21433069].

22. Karsenty G, Ferron M. The contribution of bone to whole-organism physiology. Nature. 2012;481(7381):314-20. doi: 10.1038/nature10763. [PubMed: 22258610].

23. Saag KG. Glucocorticoid-induced osteoporosis. Endocrinol Metab Clin North Am. 2003;32(1):135-57. doi:10.1016/s0889-8529(02)00064-6.

24. Biyikli NK, Emre S, Sirin A, Bilge I. Biochemical bone markers in nephrotic children. Pediatr Nephrol. 2004;19(8):869-73. doi: 10.1007/s00467-004-1537-6. [PubMed: 15206021].

25. Panczyk-Tomaszewska M, Adamczuk D, Kisiel A, Skrzypczyk P, Przedlacki J, Gorska E, et al. Markers of bone metabolism in children with nephrotic syndrome treated with corticosteroids. Adv Exp Med Biol. 2015;840:21-8. doi:10.1007/5584_2014_87. [PubMed: 25310960]. 